
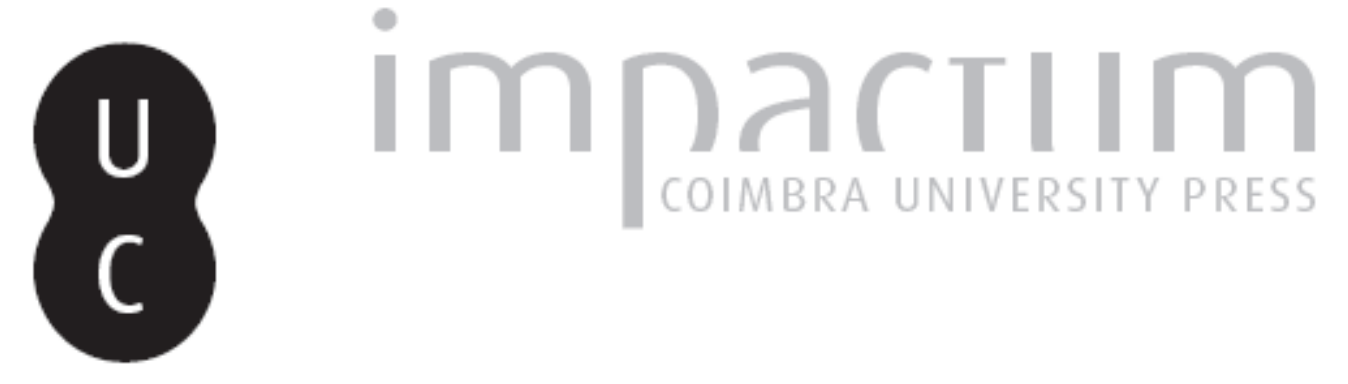

\title{
A atualidade das Humanidades
}

\section{Autor(es): $\quad$ Rodrigues, Adriano Duarte}

Publicado por: Imprensa da Universidade de Coimbra

URL persistente:

URl:http://hdl.handle.net/10316.2/37829

DOI:

DOI:http://dx.doi.org/10.14195/0870-4112_3-1_5

Accessed : $\quad$ 26-Apr-2023 15:03:12

A navegação consulta e descarregamento dos títulos inseridos nas Bibliotecas Digitais UC Digitalis, UC Pombalina e UC Impactum, pressupõem a aceitação plena e sem reservas dos Termos e Condições de Uso destas Bibliotecas Digitais, disponíveis em https://digitalis.uc.pt/pt-pt/termos.

Conforme exposto nos referidos Termos e Condições de Uso, o descarregamento de títulos de acesso restrito requer uma licença válida de autorização devendo o utilizador aceder ao(s) documento(s) a partir de um endereço de IP da instituição detentora da supramencionada licença.

Ao utilizador é apenas permitido o descarregamento para uso pessoal, pelo que o emprego do(s) título(s) descarregado(s) para outro fim, designadamente comercial, carece de autorização do respetivo autor ou editor da obra.

Na medida em que todas as obras da UC Digitalis se encontram protegidas pelo Código do Direito de Autor e Direitos Conexos e demais legislação aplicável, toda a cópia, parcial ou total, deste documento, nos casos em que é legalmente admitida, deverá conter ou fazer-se acompanhar por este aviso.

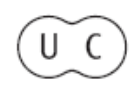




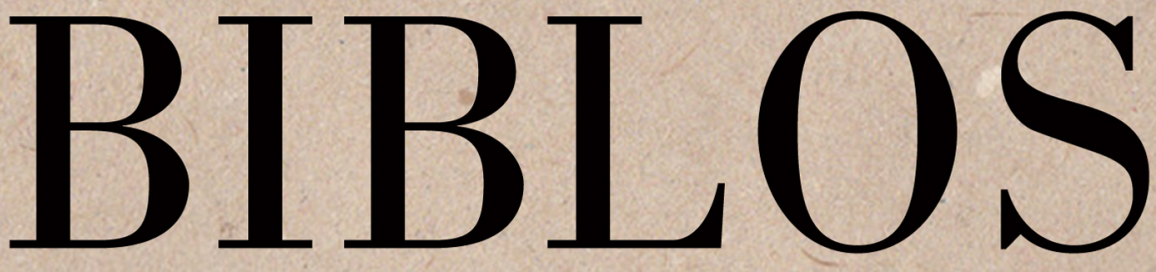

Revista da Faculdade de Letras da Universidade de Coimbra

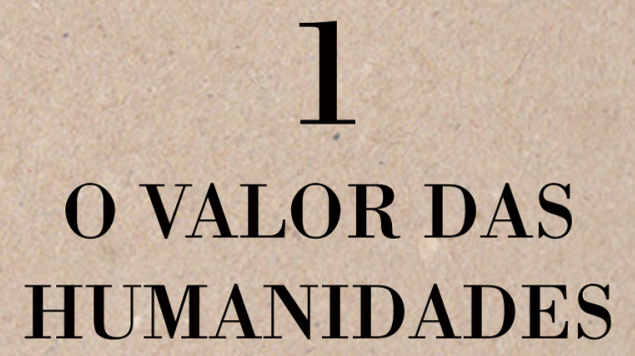

NÚMERO 1, 2015

3. ${ }^{\text {a }}$ SERIE 


\title{
A ATUALIDADE \\ DAS HUMANIDADES \\ The revelance of humanities
}

\author{
ADRIANO DUARTE RODRIGUES \\ adrigues@netcabo.pt \\ Faculdade de Ciências Sociais e Humanas da Universidade Nova de Lisboa
}

\author{
DOI \\ http://dx.doi.org/10.14195/0870-4112_3-1_5 \\ Recebido em setembro de 2014 \\ Aprovado em janeiro de 2015
}

Biblos. Número $1,2015 \cdot 3 .^{\text {a }}$ série

pp. $111-125$ 


\title{
ADRIANO DUARTE RODRIGUES
}

\section{RESUMO.}

Este texto pretende sublinhar a natureza porosa das fronteiras entre as ciências positivas, que procuram objetivar o conhecimento dos fenómenos, e as humanidades, que procuram compreender o sentido da experiência subjetiva, uma vez que as ciências positivas só podem objetivar os fenómenos do mundo de que os cientistas têm experiência subjetiva e os estudiosos das humanidades só podem compreender o sentido dos fenómenos subjetivos a partir do momento em que os conseguem objetivar. Pretende igualmente mostrar que os saberes das humanidades são incontornáveis, uma vez que deles depende o sentido das experiências, tanto individuais como coletivas, do presente.

Palavras-chave: Humanidades; Experiência subjetiva; Objetivaçăo da experiência; Sentido; Saber Disciplinar.

\begin{abstract}
.
The aim of this text is an outline of the porous nature from the bounders between positivist sciences and humanities. As positivist sciences attempt to provide objectivity to the phenomena, humanities seek to understand the sense of subjective experience. Moreover, positivist sciences can only objectivize phenomena in a world where scientists have subjective experience and humanists try to understand the logical sense from the subjective findings from the moment they manage to objectivize them. Finally, the text also tries to show how the knowledge coming from humanities is unavoidable, given that they determine the sense of both individual and collective present experiences.
\end{abstract}

Keywords: Humanities; Subjective experience; Experience objectivity; Sense; Disciplinary knowledge. 
A questão da atualidade das humanidades não é nova, mas surge sempre como nova, porque em cada época apresenta novos contornos que a diferenciam da maneira como era colocada noutras épocas. Na antiga Grécia, por exemplo, apresentava-se em torno da questão sofística, questáo que continua ainda hoje bem presente nos discursos dos autodenominados pós-modernos, para os quais a racionalidade é flexível, dependente dos interesses que se pretendem satisfazer, de acordo com a máxima de Protágoras, para quem “o homem é a medida de todas as coisas". No nosso tempo, a questão da atualidade das humanidades é inseparável do fosso que separa, por um lado, as ciências positivas, que estudam os fenómenos objetivos, e, por outro lado, as ciências humanísticas, em particular as ciências filosóficas, literárias e artísticas, que procuram dar conta da experiência subjetiva, tanto do mundo individual como do mundo coletivo.

Este fosso traduz-se hoje no confronto entre dois modelos de formação ${ }^{1}$, entre o modelo literário e erudito, por um lado, e o modelo científico do especialista e do técnico, por outro lado. Haverá então, hoje, dois critérios de verdade, o critério da lógica objetiva das proposiçôes factuais, e o critério de uma lógica subjetiva das percepçôes espontâneas do senso comum intersubjetivamente partilhado? Questão difícil, porque nos coloca perante um dilema aparentemente insolúvel. De facto, é tão difícil aceitar a validade de duas lógicas distintas, da que regula os processos de objetivação científica e da que regula a experiência subjetiva, como aceitar uma única lógica válida, nomeadamente a que regula os conhecimentos objetivantes elaborados pelas disciplinas positivas. Aceitar a existência de duas lógicas válidas é admitir a existência de duas modalidades de explicação racional, uma para os fenómenos objetivos e outra para os comportamentos individuais e coletivos, ao passo que aceitar uma única lógica válida é admitir a existência de uma única explicação racional tanto para os fenómenos do mundo natural como para a experiência subjeti-

\footnotetext{
Tomo aqui a noçấo de formaçấo no sentido que lhe dá Gadamer (Gadamer 1988: 38 e ss.), entendido como um dos "conceitos básico do humanismo" e compreende ao mesmo tempo a aquisiçăo da capacidade para formular juízos acerca da verdade, da bondade e da beleza, fundados em princípios que permitem o acesso ao geral e "requerem sacrifício da particularidade em favor da generalidade" (Gadamer 1988: 41).
} 
va. Da solução deste dilema depende a possibilidade e o futuro da distinção das humanidades em relação às ciências positivas objetivantes. Se aceitarmos que o único critério de racionalidade é o princípio que regula o processo de objetivação das ciências positivas, então as ciências que pretendem dar conta da experiência subjetiva do mundo da vida, se quiserem fazer aceitar a sua legitimidade científica, têm que seguir os mesmos princípios objetivantes das outras ciências. É este o entendimento que parece hoje prevalecer nas agências de financiamento dos projetos, a julgar pela homogeneização dos critérios de avaliação ${ }^{2}$. Se, pelo contrário, a experiência subjetiva do mundo da vida obedece a princípios lógicos específicos, distintos dos que regulam as ciências positivas, o fosso entre as ciências positivas e as humanidades é intransponível.

A ultrapassagem deste dilema é realizada concretamente, ainda que de maneira implícita, pelo investigador no quadro da sua atividade de investigação, pelo facto de, mesmo quando está envolvido na sua profissão, seguindo os protocolos de objetivação dos fenómenos, não deixar de continuar a estar inserido na experiência subjetiva, no mundo da vida, como qualquer outro ser humano, como Husserl sublinhava:

Os sábios são eles próprios homens no mundo da vida — homens entre os outros. O mundo da vida é o mundo para todos. E portanto as ciências, que são antes de mais o mundo dos sábios, existem para todos os homens como sendo a "nossa produção", como a nossa conquista (enunciados, teorias) existem para todos - tal como o mundo da vida é para todos, de maneira subjetiva relativa.

(Husserl 1976: 517)

\footnotetext{
A este propósito seria muito interessante submeter hoje os trabalhos dos professores e investigadores que trabalhavam há cinquenta anos nos domínios das humanidades à avaliação das agências de acreditação e de financiamento. Quase todos seriam reprovados, pelo menos se tivermos em conta o critério da produtividade, uma vez que muitos dos trabalhos mais marcantes que nos legaram só foram publicados a título póstumo. Recordemos, por exemplo, Charles Sanders Peirce, Ferdinand de Saussure, George Herbert Mead.
} 
O físico náo continua a falar do nascer e do pôr do sol, embora saiba que o Sol não nasce nem se póe, e não adequa o desenrolar da sua vida quotidiana com os efeitos ilusórios do fenómeno astronómico expressos pela sua maneira de falar? É por isso que o objeto das humanidades, o mundo da experiência das determinaçóes subjetivas que delimitam os objetos da percepção e das sensações, mas também definem os interesses e os objetivos, com as suas dimensóes ontológicas, éticas e estéticas, interessa de maneira particular o cientista das ciências positivas, a braços com a tarefa de objetivação dos fenómenos naturais, se quiser entender a relação entre os fenómenos cientificamente objetivados e a sua própria experiência subjetiva desses fenómenos.

Husserl via no esquecimento das determinaçóes da experiência subjetiva por parte das ciências positivas o fator principal da crise das ciências na Europa. Desde então para cá a situação não parece ter sido alterada (Husserl 1976). E a pergunta que fazia, então, sobre as condiçôes da sua superação mantém hoje a mesma atualidade. Mais do que o suposto desencantamento pelas humanidades, revelada pela suposta desafeição dos alunos que se candidatam às disciplinas humanistas, é o esquecimento do cientista da sua inserção no mundo da vida que é preocupante, pelo cada vez maior desenraizamento dos saberes em relação à experiência subjetiva do nosso mundo.

A crítica do desenraizamento das humanidades é muitas vezes entendida como afirmação da sua inutilidade: as humanidades seriam saberes desenraizados porque inúteis. $\mathrm{O}$ que torna esta questão particularmente complexa é a sua natureza teleológica: as humanidades são inúteis para quem e para o quê? Esta crítica parte, por conseguinte, de um pressuposto teleológico, o pressuposto de que a validade dos conhecimentos depende da sua utilidade. Este pressuposto tem como fundamento uma visão antropológica segundo a qual a validade da atividade humana em geral, e da atividade cognitiva, em particular, depende da sua utilidade. A questáo deverá então ser formulada de outro modo: qual é o objetivo para o qual as humanidades são úteis? Esta questão é indefinidamente aberta, uma vez que se vai alargando de maneira incomensurável à medida que o horizonte da experiência se vai abrindo 
ao longo da vida ${ }^{3}$. É como se, à medida que os anos passam, as pessoas descobrissem nas humanidades respostas para questóes que a experiência de vida foi progressivamente tornando relevantes e prioritárias. Não é, por conseguinte, possível encontrar para a questáo da utilidade das humanidades uma resposta única e definitiva. À medida que se vão confrontando com o peso da memória e com a efemeridade da existência, a curiosidade acerca da história coletiva e das diferentes maneiras de equacionar os enigmas da vida que, ao longo dos séculos, foram sendo propostas assume um relevo e uma urgência particulares, dessas propostas parecendo depender a descoberta da própria razão de existir.

A este propósito, gostaria de me debruçar agora sobre o contributo de Henri Bergson para o entendimento da relação da experiência subjetiva com o processo da sua objetivação.

\section{A NATUREZA CONTÍNUA DOS FLUXOS DA EXPERIÊNCIA SUBJETIVA}

Uma das questōes fundamentais da relaçấo das humanidades com as ciências positivas tem a ver com a possibilidade de objetivar a experiência subjetiva: como é possível ter acesso e dar conta da experiência que os seres humanos têm do mundo, de maneira a fazer dessa experiência objeto de conhecimento racionalmente válido? Não é verdade que do mundo cada um tem uma experiência própria e intransmissível?

Esta questáo tem sido sistematicamente colocada ao longo dos séculos. Retomo aqui a maneira como Henri Bergson a equacionou e como viria a ser retomada, em particular por George Herbert Mead (Mead 1992) e por Alfred Schütz (Schütz 1972: 45 ss.).

A experiência subjetiva que temos do mundo é um processo contínuo, informe. Estamos mergulhados em permanência num fluxo de percepçôes e

Não é por acaso que o número de pessoas que procuram cursos de humanidades, em particular da filosofia, da história, das artes, das línguas, aumenta com a idade. 
de sensaçóes, como a baleia no oceano. Cada um dos instantes vai dando lugar a outro, sem ruturas nem hiatos. A nossa atenção não está habitualmente fixada na experiência deste processo que nos arrasta com ele, mas nos objetivos visados pela ação em que estamos empenhados. Pelo facto de estarmos mergulhados neste processo nem sequer temos dele uma consciência clara, como dizia Alfred Schütz:

Se nós simplesmente vivemos imersos no fluxo da duração, encontramos apenas experiências indiferenciadas que se misturam umas com as outras num fluxo contínuo. Cada um dos Agoras difere essencialmente do seu precedente no facto de no Agora o precedente estar contido numa modificação retencional. No entanto, não sei nada disto enquanto estou simplesmente a viver no fluxo da duração (...).

(Schütz 1972: 51)

É verdade que os fenómenos do mundo natural se desenrolam, por definiçấo, segundo leis independentes da vontade e da intervenção humana e que por isso têm nesta independência condiçôes de objetivação que não dependem da experiência humana. No entanto, a sua delimitação e o seu agendamento nas prioridades da investigação científica dependem da sua relação com a experiência subjetiva que as pessoas e, em particular, os cientistas têm deles.

Como podemos então dar conta do fluxo contínuo da experiência em que estamos mergulhados em permanência e fazer do seu estudo uma ciência, quando nem o próprio sujeito dessa experiência tem dela consciência clara e distinta? Como é possível uma ciência dos fluxos, se para a sua constituição temos de ser capazes de discriminar as unidades discretas que delimitam os contornos dos fenómenos estudados?

À experiência dava Henri Bergson o nome de duração:

Há duas concepções possíveis da duração, uma pura de qualquer mistura, a outra em que intervém de maneira sub-reptícia a noção de espaço. A duração completamente pura é a forma que toma a sucessão de nossos estados de consciência quando o nosso eu se deixa viver, quando se abstém de fazer 
uma separação entre o estado presente e os estados anteriores. Não precisa para isso de se absorver completamente na sensação ou na ideia que passa, porque, dessa maneira, pelo contrário, deixaria de durar.

(Bergson 2007: 74-75)

É a primeira modalidade, a da duração pura, que corresponde à experiência subjetiva do mundo em que estamos mergulhados, ao fluxo dos momentos que se sucedem, ao longo dos quais cada um dos 'aqui e agora' dá lugar ao seguinte sem fronteiras nem limites claramente definidos. É só depois de terem passado, quando deixamos de os experienciar, que a reflexáo procede ao trabalho da sua objetivaçáo, recortando nesse fluxo contínuo e informe os instantes que a memória lhe fornece, de acordo com a sua relevância para aquilo que está em jogo na experiência presente. No entanto, a diversidade plástica das experiências passadas, que a memória traz à reflexâo realizada no presente, permite uma multiplicidade de objetivaçóes possíveis, o que explica por que razão desse trabalho possam resultar sempre diferentes recortes da experiência passada. Cada um de nós pode dar-se conta desta plasticidade da experiência e da consequente diversidade de objetivaçóes a que se presta, observando as diferentes maneiras de narrar experiências vividas, em função daquilo que no momento da sua narração lhe parece relevante. Paradoxalmente, a única experiência objetiva possível é sempre aquela que, diferida em relação à experiência única, irrepetível e vivida, decorre de escolhas realizadas no quadro da experiência subjetiva presente no momento da sua objetivaçáo.

Como vemos, a pluralidade das interpretaçôes da experiência subjetiva não é uma limitação do trabalho da ciência, mas a marca da diversidade plástica da experiência da duração pura, da experiência do fluxo contínuo em que estamos mergulhados no momento em que estávamos nela mergulhados. Nem todas as objetivaçôes da experiência são evidentemente possíveis, mas as possibilidades de objetivação são indefinidamente abertas, em função da diversidade das experiências presentes que a trazem à memória, que a rememoram e, deste modo, a tornam relevante.

Não são apenas as ciências humanísticas que trabalham com estas modalidades da experiência; o cientista que pretende objetivar os fenómenos, 
utilizando para o efeito os paradigmas disciplinares das ciências positivas a partir da observação dos fenómenos situados no espaço e no tempo, não pode ignorar que o recorte dos fenómenos discretos que observa e objetiva não são os únicos recortes possíveis da sua própria experiência do mundo, razáo pela qual os conhecimentos que adquire serão sempre provisórios e abertos a novos processos de objetivação.

\section{A NATUREZA DISCURSIVA DOS PROCESSOS DE OBJETIVAÇÃO DA EXPERIÊNCIA SUBJETIVA}

Como vimos, o processo de objetivação faz intervir a memória, a faculdade que fornece à consciência os materiais de que recorta os fenómenos, mas é a reflexão que produz o trabalho da sua objetivação:

Quando, pelo meu ato de reflexão, concentro a atenção na minha experiência vivida, já não estou a assumir simplesmente a vivência no seio do seu fluxo. As experiências são apreendidas, distinguidas, postas em relevo, demarcadas uma da outra; as experiências que foram constituídas como fases no seio do fluxo da duração tornam-se agora objetos de atenção enquanto experiências constituídas.

(Schütz 1992: 51)

Esta experiência objetivada pela reflexão é inseparável da sua expressão simbólica e, como tal, da sua função comunicacional. Como vemos, não é a experiência subjetiva que o cientista trabalha e de que dá conta, mas a sua objetivação simbólica, o resultado de um trabalho reflexivo, entre outros possíveis, sobre aquilo que a memória da experiência subjetiva passada lhe fornece no momento em que procede à sua objetivação simbólica.

\section{A QUESTÃO DA CLASSIFICAÇÃO DAS OBRAS}

Uma das questóes importantes decorrentes do processo de objetivação da experiência que se coloca às humanidades é a da classificação das obras. Da resposta 
a esta questão depende em grande medida a definição do ensino e a formação nos seus diferentes domínios de estudo. O debate desta questão atravessa todas as épocas, mas agudizou-se sobretudo a partir do século XVII, no quadro do projeto de renovação dos paradigmas do saber, decorrente da proposta de Descartes e da controvérsia a que deu origem. A questão coloca-se nos seguintes termos: quais as obras individuais e coletivas que devem ser guardadas, classificadas, preservadas e transmitidas ao longo das geraçôes?

Da resposta a esta questão depende o recorte dos programas de formação nas diferentes disciplinas que configuram as humanidades. Esta questão assumiu particular relevo com o processo de musealizaçáo iniciado no século XVIII, mas a partir dos anos oitenta do século passado tomou novos contornos, com o aumento exponencial da capacidade de armazenamento de dados e a generalização do acesso personalizado às bases de dados, proporcionados pelos dispositivos eletrónicos.

A única resposta possível a esta questão só a podemos encontrar se tivermos em conta a experiência presente. É a relevância das obras passadas para equacionar as questóes suscitadas pela experiência presente e para lhes dar resposta que as recorta do fluxo da história e as objetiva como notáveis. Não admira, por isso, que obras entretanto esquecidas readquiram o seu lugar de novo no catálogo das obras a preservar e a transmitir e que obras classificadas desapareçam ou sejam relegadas ao esquecimento e fiquem, assim, debaixo das cinzas da memória coletiva, aguardando que eventualmente a sua relevância seja redescoberta por novas inquietaçóes presentes.

Esta questão assume uma importância quando pretendemos repensar o lugar das humanidades no conjunto dos saberes do nosso tempo. Entre outros aspetos permite compreender por que razão a disponibilidade generalizada das bases de dados e a publicação das obras não dispensa a formação humanística. As bases de dados disponibilizam as obras, mas não formulam as questóes que na experiência presente as torna relevantes. As disciplinas humanísticas têm, por isso, mais do que a função de facilitar o acesso às obras do passado, o papel de explicitação das questôes da experiência presente que as obras do passado equacionam e para as quais propóem eventualmente soluçôes. Este é o trabalho de pesquisa das humanidades que, no nosso tempo, se tornou urgente 
e que mais nenhuma ciência pode substituir. Deste trabalho depende o próprio sentido da experiência presente.

\section{OS SENTIDOS DO SENTIDO}

Quando falamos de sentido da experiência como o objeto de investigação das humanidades podemos querer dizer coisas diferentes. É sobre a explicitação destes diferentes sentidos do sentido que gostaria agora de me debruçar.

Num artigo de 1957, Paul Grice distinguia três modalidades distintas de sentido a que deu o nome de sentido natural ou náo cognitivo, náo natural ou comunicativo e intencional ou cognitivo (Grice 1957). No primeiro caso, o sentido é a correspondência da percepção de uma manifestação sensorial com um fenómeno que o provoca mas que não é sensorialmente percepcionado: o fumo no alto de uma montanha tem sentido porque remete para a ocorrência do fogo que o provoca. No segundo caso, estamos perante uma manifestação que associamos à ocorrência de um fenómeno que lhe está associado por convenção, como quando observamos o acenar de alguém na nossa direção como uma saudação que nos é dirigida. No terceiro caso, o sentido tem a ver com a relação que estabelecemos entre um comportamento e a intenção de realizar de um determinado ato, como, por exemplo, associamos o gesto de alguém a retirar as chaves do bolso com a intenção de abrir a porta do carro. Para evitar a ambiguidade do termo "natural" prefiro designar a primeira modalidade de sentido como indiciária ou sintomática, à segunda como convencional, mantendo a designação de intencional para a terceira modalidade. Quando disse, no fim do parágrafo anterior, que a classificação das obras resulta da sua relação com o sentido atribuído à experiência do presente, de que modalidade de sentido estou a falar? Não estou propriamente a falar de uma relação sintomática entre uma obra do passado e a experiência do presente, como se a experiência presente fosse o efeito natural visível dessa obra do passado. Também não se trata de uma relação convencional nem de uma relaçáo intencional entre a experiência do presente e uma obra do passado. Quando, por exemplo, no século xiI, Averrois colocou a obra de Aristóteles no horizonte do pensamento ocidental da Idade Média, quando, no século XviıI, a obra musical de Jean Sebastian Bach foi redescoberta e passou a influenciar a 
produção musical do Ocidente, quando, em Portugal, o Estado Novo reabilitou os como obra emblemática da ideologia imperial do regime político, assistimos a um processo de reinterpretaçấo de uma obra do passado, redefinindo-a como protótipo ou modelo para a mobilizaçáo coletiva em torno de projetos a realizar no presente, ora no domínio do pensamento, ora no domínio estético, ora no domínio político. É este o sentido que os estudos humanísticos têm por objetivo estudar, de modo a explicitarem os questionamentos da experiência do presente e a prepararem, deste modo, projetos coletivamente mobilizadores para o futuro. É por isso que a crise das humanidades corresponde à crise da mobilizaçáo da comunidade, a uma desistência da procura de respostas para as incertezas da vida, a uma delimitação do seu horizonte da experiência presente à fruiçáo fugaz e imediata das oportunidades e ao seu esgotamento.

Numa obra póstuma, foram reunidos num volume uma série de ensaios de Italo Calvino. O título é uma pergunta: . Uma das resposta que o autor dá a esta pergunta pode muito bem ser a que poderíamos também encontrar para a pergunta: Porquê as humanidades?

O nosso clássico é o que não pode ser-nos indiferente e que nos serve para nos definirmos a nós mesmos em relação e se calhar até em contraste com ele. (Calvino 1994: 11)

À medida que nos vamos deixando fascinar pelo sucesso imediato dos inventos técnicos e afastando dos saberes clássicos, assistimos a uma busca de modos de vida alternativos e a um interesse cada vez mais empenhado pelo saber dos antigos, o que parece indiciar uma nostalgia da sabedoria de que as humanidades precisamente guardam a memória. O retorno ao campo, a procura de modos de vida alternativos à vida nas cidades, a prática da meditação, a busca de comportamentos saudáveis são as marcas mais visíveis deste paradoxo.

\section{AS ANTINOMIAS DA DISCIPLINARIDADE DOS SABERES}

Um dos aspetos marcantes do fosso entre as ciências objetivantes e os saberes das humanidades é a natureza do devir disciplinar dos conhecimentos, 
decorrente das exigências metódicas dos processos de descoberta. Enquanto as ciências objetivantes tendem a definir as fronteiras das disciplinas em função das configuraçôes dos fenómenos observados, as ciências a que habitualmente damos o nome de humanidades recortam os seus perfis disciplinares segundo critérios que combinam as configuraçôes dos fenómenos com as diferentes perspetivas das suas abordagens. Decorre desta distinção uma relativa indefinição das humanidades e a consequente proliferação das disciplinas que as integram. Assistimos, assim, ao surgimento de disciplinas de definição problemática e de aceitação discutível pelos que não adotam as mesmas perspetivas, acusando-as de corresponderem mais à vontade de criação de espaços de afirmação de projetos pessoais e de visarem objetivos promocionais das escolas, acossadas pelas exigências concorrenciais da sua sobrevivência, do que a verdadeiros domínios científicos distintos. Embora a proliferação dos cursos no ensino superior se verifique em todos os domínios do saber, é sobretudo nas humanidades que tem representado uma tendência mais evidente e preocupante.

Uma questão que hoje se torna, por conseguinte, central tem a ver com o próprio recorte das áreas científicas em geral e com a delimitação dos saberes das humanidades. Numa primeira aproximação, as humanidades recobrem a filosofia, as letras, a história e as belas artes. Mas este recorte tornou-se particularmente problemático, uma vez que assistimos, por um lado, ao surgimento de saberes positivos de cariz objetivante nos domínios tradicionalmente afetos às humanidades e, por outro lado, ao desenvolvimento de saberes de cariz hermenêutico da experiência subjetiva em domínios científicos objetivantes. Como recusar, por exemplo, à antropologia ou à sua microssociologia a sua natureza humanística, quando procuram dar conta da própria experiência humana, a partir do seu enraizamento comunitário e dos conhecimentos do sentido comum intersubjetivamente partilhado? Por outro lado, como recusar, por exemplo, a inserção das abordagens sistémicas da sociedade no domínio das ciências objetivantes? Quando olhamos para o que os investigadores fazem e publicam temos de aceitar que as fronteiras entre as humanidades e as ciências objetivantes se tornaram particularmente porosas e muitas vezes inexistentes. 


\section{CONCLUSÃO}

É muito provável que a desafeição pelas humanidades decorra da sua escolarização, ao facto de compreenderem domínios de saber que se converteram em currículos académicos e, deste modo, terem passado a ser constituídas por conhecimentos impostos pela instituição escolar, encarados por isso como conhecimentos formais desenraizados da experiência.

Refletir sobre o estado atual dos cursos de humanidades é uma tarefa cheia de embustes porque mobiliza em geral dois fantasmas antagónicos que, em todas as épocas e em todas as sociedades, povoam o imaginário das pessoas perante a mudança, o fantasma demoníaco e o fantasma faustiano. Ou, se preferirem, a tensão entre a visão profética e a visão messiânica da cultura. Para os proféticos, o novo é sempre deterioração da pureza e da plenitude do modelo originário e o discurso sobre esta deterioração cumpre um papel profético de apelo ao retorno do modelo originário perdido. Para os messiânicos, o novo é sempre um avanço em direção à plenitude por vir e o discurso sobre esta plenitude por vir cumpre o papel messiânico que visa incentivar a abertura de caminhos para a alcançar. O discurso acerca do lugar atual das humanidades é indiscutivelmente uma das manifestaçôes da tensão entre estas duas visões antagónicas do novo. Vemos neste antagonismo o confronto dos ideais românticos, agarrados à nostalgia, à dor pela perda do paraíso perdido, com os ideais progressistas, empenhados na procura da alvorada antevista. Como vemos, os discursos sobre a atualidade das humanidades só podem ser encarados à luz de uma filosofia da história.

É frequente encontrar professores das Faculdades de Letras que encaram esta discussão a partir de uma visão profética ou romântica, vendo a situação atual das humanidades como uma desafeição generalizada e como um sintoma da atual miséria cultural da humanidade, como desaparecimento da aura passada da sabedoria.

Mas há ainda uma outra razão para a atual crise das humanidades e que tem a ver com o diagnóstico que, já em 1936, Edmund Husserl fazia da crise das ciências europeias, crise que parece decorrer curiosamente, não da sua falência, mas da natureza do seu sucesso. A relação do sucesso das ciências com a desafeição das humanidades decorre do facto de as ciências, por um 
lado, terem limitado o alcance do seu objeto aos fenómenos observados e, por outro lado, terem abandonado da sua indagação aquilo a que os alemães dão o nome de, de mundo da vida. Deste modo, enquanto reservaram para si as experiências objetivas observadas, deixaram de se interessar pela experiência, pelo mundo da subjetividade, mundo que, com as suas diferentes vertentes, constituiu precisamente, desde a aurora do pensamento racional, o centro da reflexão das humanidades.

Uma das consequências mais evidentes deste processo de objetivação dos saberes foi a sua fragmentação disciplinar e a consequente possibilidade de formaçáo de especialistas tanto mais competentes quanto menos conhecedores da relação das suas competências com o mundo da vida, com a experiência concretamente vivida pelas pessoas dos fenómenos objetivados pela sua disciplina. $\mathrm{O}$ cientista corre, assim, o risco de saber objetivar os fenómenos da rotação da terra com o rigor da matemática, sem entender nem saber dar conta da experiência estética do espetáculo diário daquilo a que na linguagem comum damos o nome de nascer do Sol. Uma das manifestaçôes da desafeição das humanidades é o embotamento da sensibilidade que faz a especificidade da presença dos homens e mulheres no mundo, a incapacidade de se emocionar perante os fenómenos, limitando a sua ciência à procura das suas razóes objetivas.

\section{BIBLIOGRAFIA}

Bergson, Henri [1889] (2007). Essai sur les donnés immédiates de la conscience. Quadrigue, PUF, 2007 (original: 1889)

Calvino, Italo (1994). Porquê ler os clássicos. Trad. José Colaço Barreiros. Lisboa: Teorema.

Gadamer, Hans-George (1988). Verdad y método. Trad. Ana Agud Aparicio, Rafael de Agapito. Salamanca: Sígueme.

Grice, Paul (1957). "Meaning”, Philosophical Review, 56, 377-388.

Husserl, Edmund (1976). La crise des sciences européennes et la phénoménologie transcendantale. Trad. Gérard Granel. Paris: Gallimard, 1976.

Mead, George Herbert [1932] (1992). Mind, Self and Society: From the Standpoint of a Social Behaviorist. Chicago: University of Chicago Press.

Schütz, Alfred (1972). The Phenomenology of the Social World. Northwestern: University Press. 